\title{
Clinical outcomes of blood transfusion to patients with pelvic fracture in the initial $6 \mathrm{~h}$ from injury
}

\author{
QING YANG $^{1 *}$, TING WANG $^{2 *}$, LEI AI $^{3}$, KAI JIANG $^{1}$, XINGGUANG TAO $^{1}$, \\ DONGLIANG GONG ${ }^{1}$, NONG CHEN ${ }^{1}$, YANG FU ${ }^{1}$ and FUGEN PAN ${ }^{1}$
}

\begin{abstract}
${ }^{1}$ Department of Orthopedics, QingPu Branch of Zhongshan Hospital Affiliated to Fudan University, Qingpu District Central Hospital of Shanghai, Shanghai 201700; ${ }^{2}$ Department of Gastroenterology, Shanghai General Hospital, Shanghai Jiao Tong University, Shanghai 201600; ${ }^{3}$ Department of Laboratory, Taishan Coal Sanatorium, Taian,
\end{abstract}

Shangdong 201700, P.R. China

Received May 18, 2019; Accepted December 2, 2019

DOI: $10.3892 /$ etm.2020.8445

\begin{abstract}
As part of the treatment of pelvic fracture, major hemorrhage poses a challenge for trauma surgeons. The aim of the present study was to evaluate the clinical outcomes of blood transfusion in the initial $6 \mathrm{~h}$ after pelvic fracture, and to define the blood transfusion volume required for each pelvic fracture type. A retrospective cohort study was performed on patients with pelvic fracture at a single Level I Trauma Centre over a 3-year period. A total of 1,297 patients were transported to our trauma centre within $2 \mathrm{~h}$ of injury and blood transfusion was administered in the initial $6 \mathrm{~h}$ after pelvic fracture. Review of the patients' medical records provided the initial pelvic radiographs and data from emergency department care. Clinical outcomes, including frequency of blood transfusion, blood transfusion volume, injury severity scores and mortality, were evaluated. All pelvic fractures were defined as closed fractures and patients were categorized according to the Arbeit fuer Osteosynthese (AO) classification system. Statistical methods were used to identify trends to provide guidance for clinical prediction. Complete data were available for 497 patients with pelvic fracture, 104 (20.9\%) of which received blood transfusion. The blood transfusion volume in the initial $6 \mathrm{~h}$ ranged from 0 to $10,000 \mathrm{ml}$, with a mean of $1,213.94 \pm 1354.11 \mathrm{ml}$. The total mortality rate was $1.8 \%$. Among the patients with C-type pelvic fractures, the frequency of blood transfusion was $59.0 \%$ and the mean volume was $2,191.30 \pm 1,740.93 \mathrm{ml}$.
\end{abstract}

Correspondence to: Dr Yang Fu or Dr Fugen Pan, Department of Orthopedics, QingPu Branch of Zhongshan Hospital Affiliated to Fudan University, Qingpu District Central Hospital of Shanghai, 1158 East Gongyuan Road, Qingpu, Shanghai 201700, P.R. China

E-mail: fu255@126.com

E-mail: panfugen123@126.com

${ }^{*}$ Contributed equally

Key words: pelvic fracture, hemorrhage, transfusion, prediction rule
The mortality rate for C-type pelvic fractures was $11.43 \%$. The B3 subtype of pelvic fractures had the highest transfusion frequency (53.6\%), while the $\mathrm{C} 3$ subtype had the largest blood transfusion volume $(5,700.00 \pm 4,666.90 \mathrm{ml})$. Patients with type A-C pelvic fractures had a progressively larger mean transfusion volume, transfusion frequency and mortality in the initial $6 \mathrm{~h}$ after pelvic fracture. The AO classification system was demonstrated to be a useful tool for the identification of pelvic fracture risk in the present study.

\section{Introduction}

Selection of the optimal treatment of major hemorrhage in patients with pelvic fracture remains a challenge for trauma surgeons (1-7). Uncontrollable major hemorrhage is a major cause of mortality in patients with pelvic fractures (8-11). Relatively aggressive measures are imperative to manage this serious pathophysiological status; blood transfusion is an effective protocol for the improvement of the hypovolemic status and the use of other supportive care measures, including external fixations, angiography and embolization, as well as pre-peritoneal pelvic packing, may also be effective (8-11). Previous studies have revealed that high-energy pelvic fracture is associated with a relatively higher blood transfusion frequency (12-14). These studies reported that blood transfusion is required at 24 (12), 48 (14) or $72 \mathrm{~h}$ (13). The Young and Burgess classification system (3) has been used to indicate the requirement for blood transfusion. However, blood transfusion administered in the initial $6 \mathrm{~h}$ after pelvic fracture is essential for the emergency treatment of pelvic fracture, which may improve the hypovolemic status immediately and decrease predictable mortality and morbidity. In addition, the Arbeit fuer Osteosynthese (AO) classification (15) of pelvic fractures has not been well investigated with regard to the blood transfusion volume. Type A is defined as a stable pelvic fracture, type $\mathrm{B}$ as rotationally unstable and type $\mathrm{C}$ as rotationally and vertically unstable fracture.

The aim of the present study was to evaluate the clinical outcomes of pelvic fracture and determine the blood transfusion volume required in the initial $6 \mathrm{~h}$ in association with the pelvic fracture type. The AO classification system was used to 
categorize patients into pelvic fracture subgroups and determine any association with blood transfusion. These results will help guide transfusion requirements and identify the optimal treatment for patients in the initial $6 \mathrm{~h}$ after pelvic fracture.

\section{Patients and methods}

Patients. Patients with pelvic fractures admitted to a Level I Trauma Centre in the Qingpu Branch of Zhongshan Hospital affiliated to Fudan University (Shanghai, China) between January 2014 and December 2016 were retrospectively identified using CT scanning images from the Emergency Registry of the Qingpu Branch of Zhongshan Hospital affiliated to Fudan University (Shanghai, China). Demographic data, abbreviated injury scale (16), injury severity score (ISS) (17) and blood transfusion requirements in the initial $6 \mathrm{~h}$ after presentation of patients with pelvic fracture to the trauma centre were recorded.

Closed pelvic fractures were included in the present study. Open pelvic fractures, pediatric pelvic fractures and severe soft tissue injuries were excluded. Additionally, patients with major internal bleeding, severe illness (hypertension, heart disease and diabetes mellitus) and abnormal coagulation diseases were excluded to diminish their influence on the investigation. Complete data were available for 497 patients with pelvic fracture. Mortality was defined as the proportion of deaths among patients with different types of pelvic fractures, whilst the morbidity was defined as the proportion of patients with pelvic fractures out of all trauma cases (1297) who were transported to the trauma center within $2 \mathrm{~h}$ of injury.

Radiographic classification. Patients were subjected to radiological examination according to the guidelines of Advanced Trauma Life Support (18). CT scanning was performed using a 64-slice multidetector CT scanner with automated tube current modulation (Lightspeed 64VCT; GE Healthcare) to determine the pelvic fracture type and other body system injuries on radiographs. A fellowship-trained orthopedic traumatologist with $>10$ years of experience and the institution's primary surgeon retrospectively classified the fractures according to the AO classification system.

Blood transfusion and emergency measures. The indications for blood transfusion for pelvic fracture patients are systolic blood pressure of $<90 \mathrm{mmHg}$, heart frequency $>130 \mathrm{bpm}$ and clinical symptoms of shock. In an emergency, combined transfusion of red blood cells, plasma and platelets (6-4-1) is preferred (19). A baseline blood sample is collected prior to blood transfusion. A pelvic belt is used for pre-hospital care. Focused assessment with sonography for trauma (FAST) (20) ultrasound is used to detect free intraperitoneal effusion in B- and C-type pelvic fractures. A positive FAST examination should be followed by laparotomy when indicated, for further investigation of the abdominal injuries and hemorrhage. External fixations are used to control the rotationally unstable pelvic fractures in the emergency room. Angiography and embolism are useful for patients with arterial injuries and pre-peritoneal pelvic packing may be an effective measure for patients with combined abdominal injury and require emergency laparotomy.
Statistical analysis. The Kruskal-Wallis test was used to compare the volume of blood transfusion among pelvic fracture types. The frequency of blood transfusion was compared using a $\chi^{2}$ test for categorical variables and one-way ANOVA followed by Student-Newman-Keuls post hoc test were applied for continuous variables. Statistical analysis was performed using SAS version 9.1 (SAS Institute). $\mathrm{P}<0.01$ was considered to indicate a statistically significant difference.

\section{Results}

General data. Complete data were available for 497 patients with pelvic fracture (Table I). The mean age of the patients included in the study was $32 \pm 16.5$ years (range, $18-48$ years) and 276 patients were male $(55.5 \%)$, while 203 patients were female $(44.5 \%)$. The mechanism of injury was high-energy impact, including traffic collision and fall from height. In the present study, 31 patients had a systolic blood pressure of $<90 \mathrm{mmHg}$, accounting for $6.2 \%$ of all cases, and 44 patients had a heart frequency of $>130$ beats per min, accounting for $8.9 \%$ of all cases. A total of 104 (20.9\%) patients received blood transfusion, with a blood transfusion volume range of $0-10,000 \mathrm{ml}$ in the first $6 \mathrm{~h}$ (mean, 1,213.94 $\pm 1,354.11 \mathrm{ml}$ ).

Blood transfusion. The mean blood transfusion volume was $437.76 \pm 282.02 \mathrm{ml}$ for type A, 1,603.13 $\pm 1,203.28 \mathrm{ml}$ for type B and 2,191.30 $1,740.93 \mathrm{ml}$ for type C pelvic fractures (Table II). The Kruskal-Wallis test was used to compare the blood transfusion volume among pelvic fracture types. The results indicated a larger mean blood transfusion volume in patients with C-type pelvic fractures as compared with that in the other types $\left(\chi^{2}=46.6789\right.$, degrees of freedom, $\mathrm{F}=2 ; \mathrm{P}<0.01$; Fig. 1).

The distribution of the blood transfusion volume in each pelvic fracture type was explored. There were 51 patients with a transfusion volume of $<600 \mathrm{ml}(49.0 \%), 23(22.1 \%)$ with a transfusion volume of $600-1500 \mathrm{ml}$ and 30 (28.9\%) with a transfusion volume of $>1,500 \mathrm{ml}$ (Table III). The frequency of blood transfusion in the three pelvic fracture types was determined using the $\chi^{2}$ test. The results indicated that patients with C-type pelvic fractures were significantly more likely to require a blood transfusion $(59.0 \%)$ than patients with $\mathrm{A}$ and $\mathrm{B}$ types (12.4 and 50.1\%, respectively; $\mathrm{F}=4, \chi^{2}=56.9067$, $\mathrm{P}<0.01)$. Massive blood transfusion was defined as $>1,500 \mathrm{ml}$ and compared among the groups using the $\chi^{2}$ test. The results indicated that patients with $\mathrm{C}$-type pelvic fractures were significantly more likely to require massive blood transfusion $\left(\mathrm{F}=2, \chi^{2}=39.7562, \mathrm{P}<0.0001\right)$.

Patients with pelvic fracture were classified into subtypes according to the AO classification system. The blood transfusion volume in the subtypes was compared. The B3 subtype was indicated to have the highest transfusion frequency, followed by the C3, C1, B2 and C2 subtypes (Fig. 2). Statistical analysis was not performed due to the limited numbers of subtypes. The mean transfusion volume for the $\mathrm{C} 3$ subtype was the largest, followed by the B1, C2, C1, B3 and B2 subtypes (Table IV).

Comparison of the ISS among the pelvic fracture types was performed using the Kruskal-Wallis test (Table V). It was indicated that the ISS in the C-type pelvic fracture group was higher than that for types $\mathrm{A}$ and $\mathrm{B}\left(\chi^{2}=106.8412, \mathrm{~F}=2, \mathrm{P}<0.01\right)$. 
Table I. General characteristics of the patients $(n=497)$.

\begin{tabular}{|c|c|}
\hline Characteristic & Value \\
\hline Age (years) & $32 \pm 16.5$ \\
\hline \multicolumn{2}{|l|}{ Gender } \\
\hline Male & $276(55.5)$ \\
\hline Female & $221(44.5)$ \\
\hline Mean ISS & $16 \pm 9.08$ \\
\hline \multicolumn{2}{|l|}{ Cause of injury } \\
\hline Motor vehicle collision & $306(61.6)$ \\
\hline Fall from height & $129(26.0)$ \\
\hline Crush injury & $35(7.0)$ \\
\hline Fall on the ground & $22(4.4)$ \\
\hline Other & $5(1.0)$ \\
\hline \multicolumn{2}{|l|}{ AO classification } \\
\hline $\mathrm{A}$ & $395(79.5)$ \\
\hline A1 & $16(3.2)$ \\
\hline $\mathrm{A} 2$ & $216(43.5)$ \\
\hline A3 & $163(32.8)$ \\
\hline $\mathrm{B}$ & $63(12.7)$ \\
\hline B1 & $18(3.6)$ \\
\hline B2 & $39(7.9)$ \\
\hline B3 & $6(1.2)$ \\
\hline $\mathrm{C}$ & $39(7.9)$ \\
\hline $\mathrm{C} 1$ & $26(5.2)$ \\
\hline $\mathrm{C} 2$ & $10(2.0)$ \\
\hline $\mathrm{C} 3$ & $3(0.6)$ \\
\hline FAST & + \\
\hline $\mathrm{B}$ & $23(36.5)$ \\
\hline $\mathrm{C}$ & $20(51.3)$ \\
\hline Systolic blood pressure $<90 \mathrm{mmHg}$ & $31(6.2)$ \\
\hline Heart frequency $>130$ beats per minute & $44(8.9)$ \\
\hline Number of blood transfusion & $104(20.9)$ \\
\hline Mean volume of blood transfusion (ml) & $1213.94 \pm 1354.11$ \\
\hline
\end{tabular}

Values are expressed as the mean \pm standard deviation or $\mathrm{n}(\%)$. AO, Arbeit fuer Osteosynthese; ISS, injury severity score; FAST, Focused Assessment with Sonography for Trauma.

A total of 23 of the 63 patients with B-type pelvic fractures $(36.5 \%)$ and 20 of the 39 patients with C-type pelvic fractures $(51.3 \%)$ had a positive FAST result (Table I). A positive FAST examination should be followed by laparotomy when indicated, in order to further investigate the abdominal injuries and hemorrhage (20). External fixation was used in 96 patients, angiography was performed to identify arterial hemorrhage and embolism in 9 patients with pelvic fractures. Pre-peritoneal pelvic packing was performed in 5 patients to treat venous hemorrhage. In addition, 150/497 (30.2\%) of fracture patients were hospitalized (mean stay, $18 \pm 6.5$ days) and 59 were admitted to the intensive care unit (ICU; mean stay, $9 \pm 7.3$ days). Comparison of the hospital and ICU days among the pelvic fracture types was performed using Kruskal-Wallis tests (Table VI). The mean hospital stay was found to be
Table II. Blood transfusion and transfusion volume compared among different AO types.

\begin{tabular}{lcrc}
\hline AO type & Patients $(\mathrm{n})$ & Transfusion & \multicolumn{1}{c}{ Volume (ml) } \\
\hline A & 395 & $49(12.4)$ & $437.76 \pm 282.02$ \\
B & 63 & $32(50.1)$ & $1,603.13 \pm 1,203.28$ \\
C & 39 & $323(59.0)$ & $2,191.30 \pm 1,740.93^{\mathrm{a}}$ \\
Total & 497 & $104(20.9)$ & \\
\hline
\end{tabular}

${ }^{\mathrm{a}} \mathrm{P}<0.01, \chi^{2}=46.6789$ and $\mathrm{F}=2$ vs. type $\mathrm{A}$ and $\mathrm{B}$. Values are expressed as the mean \pm standard deviation or $\mathrm{n}(\%)$. AO, Arbeit fuer Osteosynthese.

Table III. Distribution of blood transfusion (n).

\begin{tabular}{lcccc}
\hline & \multicolumn{2}{c}{ Volume of blood transfusion $(\mathrm{ml})$} & \\
\cline { 2 - 4 } AO type & $<600$ & $600-1,500$ & $>1,500^{\mathrm{b}}$ & Total \\
\hline A & $42(79.3)$ & $7(30.4)$ & $0(0)$ & 49 \\
B & $7(15.1)$ & $10(39.1)$ & $15(53.6)$ & 32 \\
C & $2(5.7)$ & $6(30.4)$ & $15(46.4)$ & $23^{\mathrm{a}}$ \\
Total & 51 & 23 & 30 & 104 \\
\hline
\end{tabular}

${ }^{\mathrm{a}} \mathrm{P}<0.01, \mathrm{~F}=4, \chi^{2}=56.9067$ vs. fracture $\mathrm{A}$ and $\mathrm{B}$ and ${ }^{\mathrm{b}} \mathrm{P}<0.0001, \mathrm{~F}=2$, $\chi^{2}=39.7562$ vs. fracture A and B. Values are expressed as n (\%). AO, Arbeit fuer Osteosynthese.

$10 \pm 2.0$ days in type $\mathrm{A}(69,17.5 \%), 14 \pm 4.1$ days in type $\mathrm{B}$ $(42,66.7 \%)$, and $24 \pm 3.8$ days in type C $(39,100 \%)$. The mean ICU stay was found to be $7 \pm 5.2$ days in type B $(24,38.1 \%)$ and $16 \pm 4.7$ days in type $\mathrm{C}(35,89.7 \%)$. The results indicated that the number of days of stay at the hospital and at the ICU of the C-type pelvic fracture group were higher than those for types $\mathrm{A}$ and $\mathrm{B}(\mathrm{P}<0.01)$. A total of 18 patients contracted an infection, all of which were treated with antibiotics and debridement. The infection was cured in all patients. A total of 12 patients with pelvic fracture eventually suffered disability of varying degrees.

Mortality and morbidity. A total of 9 patients died in the present study, 4 of which were categorized as type B, 4 as type $\mathrm{C}$ and 1 as type $\mathrm{A}$. The overall mortality rate in the present cohort was $1.8 \%$. The 9 patients who died had suffered multiple injuries, including head $(n=3)$, thoracic $(n=3)$, abdominal $(n=2)$ spinal $(n=2)$ and limb injury $(n=2)$. High ISS were observed in those patients (mean ISS, 29). The mean volume of blood transfusion was $1,816 \mathrm{ml}$ in the initial $6 \mathrm{~h}$ for patients who died; specifically, it was 1,200 ml in type $\mathrm{A}, 1,686 \mathrm{ml}$ in type $\mathrm{B}$ and $2,100 \mathrm{ml}$ in type $\mathrm{C}$ (Table VII).

The association between mortality and pelvic fracture type was determined using the $\chi^{2}$ test (Table VII). The mortality of each pelvic fracture type was $0.3 \%$ (1/395) for type A, $6.3 \%$ (4/63) for type B and $10.3 \%$ (4/39) for type C. The results 


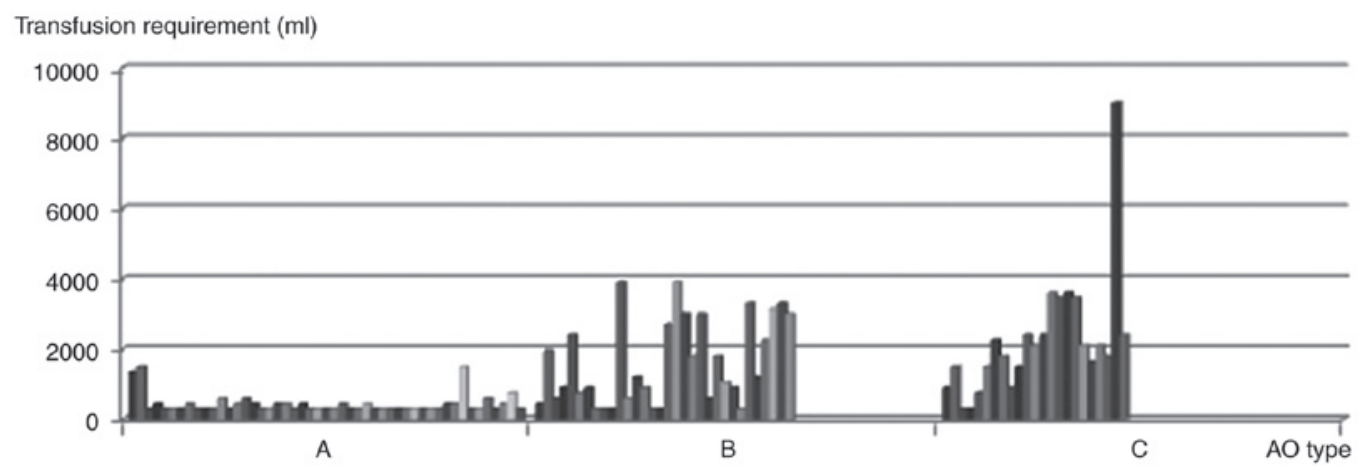

Figure 1. Transfusion requirement by AO type. The AO type of pelvic fractures is displayed on the X-axis, whilst the Y-axis indicates the volume of blood transfusion in ml. Each column represents the amount of blood transfusion required with each different AO type of pelvic fractures. It shows a larger mean blood transfusion volume in $\mathrm{C}$ type pelvic fractures, as compared to the other types $\left(\chi^{2}=46.6789, \mathrm{~F}=2, \mathrm{P}<0.01\right)$. AO, Arbeit fuer Osteosynthese.

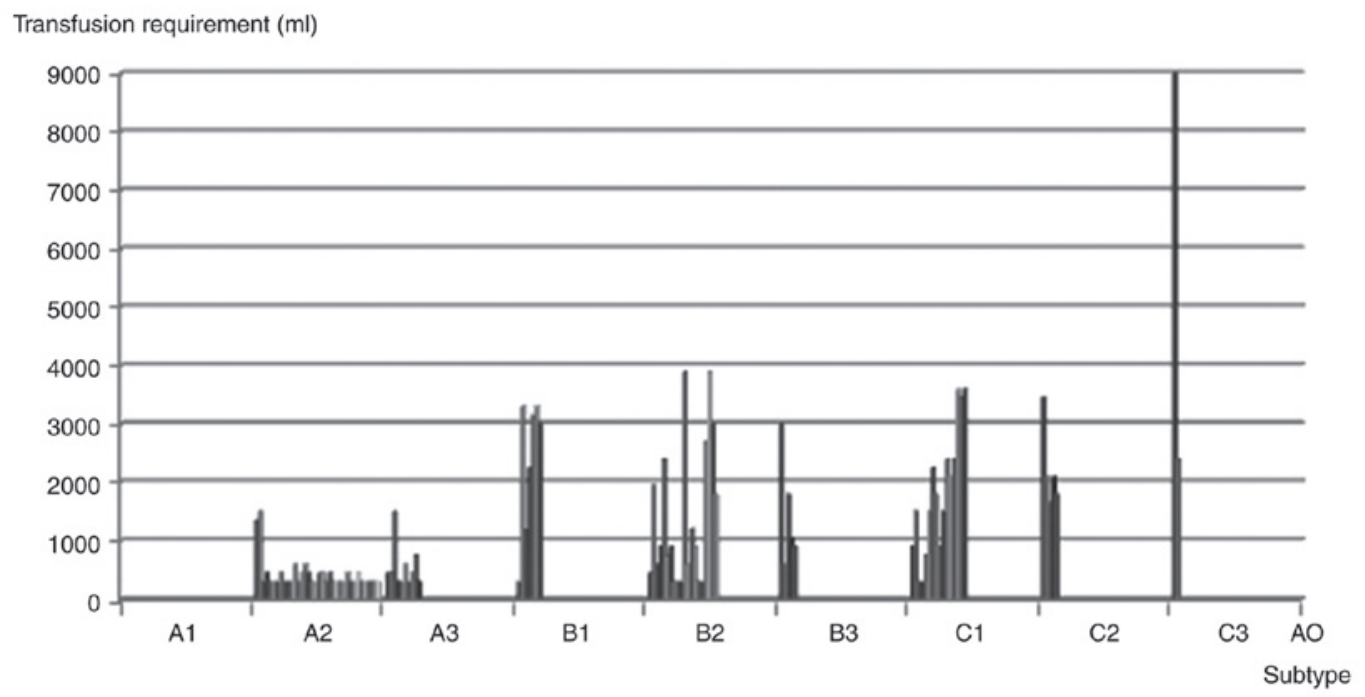

Figure 2. Transfusion requirement by $\mathrm{AO}$ subtype of pelvic fractures. The AO subtype of pelvic fractures is displayed on the $\mathrm{X}$-axis, while the $\mathrm{Y}$-axis indicates the volume of blood transfusion. Each column represents the amount of blood transfusion required with each different AO type of pelvic fractures. It was indicated that the B3 subtype had the highest transfusion frequency, while the C3 subtype had the largest volume of blood transfusion. AO, Arbeit fuer Osteosynthese.

suggested that the mortality in type $\mathrm{C}$ was higher than that in types $\mathrm{A}$ and $\mathrm{B}\left(\mathrm{F}=2, \chi^{2}=28.3328, \mathrm{P}<0.0001\right)$.

The morbidity of each pelvic fracture type was $30.5 \%$ $(395 / 1,297)$ for type A, $4.8 \%(63 / 1,297)$ for type B and $3.0 \%$ $(39 / 1,297)$ for type C. Comparison of the morbidity among the pelvic fracture types was performed using the $\chi^{2}$ test. The results suggested that the morbidity in type $\mathrm{A}$ was higher than that in $\mathrm{B}$ and $\mathrm{C}(\mathrm{P}<0.01)$.

\section{Discussion}

The clinical data provided in the present study revealed that the blood transfusion frequency and volume increased with the severity of pelvic ring disruptions. The B3 subtype with injuries in the bilateral sacroiliac joints had the highest transfusion frequency, while the $\mathrm{C} 3$ subtype with severe displacement of pelvic fracture received the largest blood transfusion volume.

High-energy impact of the anterior pelvic ring changes the volume of the pelvis and pressure status, resulting in major hemorrhage $(5,11,13,21-23)$. A vertical displacement of the pelvic fracture is likely to lead to vessel ruptures $(5,8,22,24)$. Previous studies have reported the clinical outcomes of blood transfusion in pelvic fracture patients and attempted to associate the requirement for, frequency and volume of blood transfusion with the pelvic fracture type $(1-5,9,13,14,21,22)$. The Young and Burgess classification system is used to determine the requirement for blood transfusion. The anteroposterior compression (APC II and III) and lateral compression (LC III) types have been indicated to require a higher blood transfusion volume and be associated with high mortality $(3,5,8,12,22)$. On the contrary, certain studies have been unable to demonstrate that pelvic fracture types comprise a clinical predictor of blood transfusion volume and frequency $(4,21,25)$. Magnussen et al (12) reported that nearly $50 \%(10 / 25)$ of APC II and III or LC III injuries require significant blood transfusion (3.5-12.0 units) in the first $24 \mathrm{~h}$ after injury. Furthermore, patients with an APC III-type pelvic fracture had a transfusion frequency of $61 \%$ and transfusion volume of 12.6 units. Hamill et al (22) reported on 76 patients transfused with 6 or more units of blood in the first $24 \mathrm{~h}$. The mean blood transfusion requirement in the 
Table IV. Blood transfusion and transfusion volume compared among AO subtypes.

\begin{tabular}{lccc}
\hline $\begin{array}{l}\text { AO } \\
\text { subtype }\end{array}$ & Patients (n) & $\begin{array}{c}\text { Blood } \\
\text { transfusion }\end{array}$ & Volume (ml) \\
\hline A1 & 16 & $0(0)$ & 0 \\
A2 & 216 & $39(18.1)$ & $407.69 \pm 255.09$ \\
A3 & 163 & $10(6.1)$ & $540.00 \pm 368.78$ \\
B1 & 18 & $7(38.9)$ & $2357.14 \pm 1183.37$ \\
B2 & 39 & $20(51.3)$ & $1372.50 \pm 1206.18$ \\
B3 & 6 & $5(83.3)$ & $1470.00 \pm 962.81$ \\
C1 & 26 & $16(61.5)$ & $1743.75 \pm 1000.81$ \\
C2 & 10 & $5(50.0)$ & $2220.00 \pm 714.67$ \\
C3 & 3 & $2(66.7)$ & $5700.00 \pm 4666.90$ \\
Total & 497 & $104(20.9)$ & \\
\hline
\end{tabular}

Values are expressed as the mean \pm standard deviation or $\mathrm{n}(\%)$. AO, Arbeit fuer Osteosynthese.

Table V. ISS of different AO types.

\begin{tabular}{lcc}
\hline AO type & Patients $(\mathrm{n})$ & ISS \\
\hline A & 395 & $8.93 \pm 6.38$ \\
B & 63 & $17.95 \pm 9.21$ \\
C & 39 & $19.46 \pm 6.12^{\text {a }}$ \\
\hline
\end{tabular}

${ }^{\mathrm{a}} \mathrm{P}<0.01, \chi^{2}=106.8412, \mathrm{~F}=2$ vs. fracture $\mathrm{A}$ and $\mathrm{B}$. Values are expressed as the mean \pm standard deviation. AO, Arbeit fuer Osteosynthese; ISS, injury severity score.

first $6 \mathrm{~h}$ from injury was 14 units in embolized and 8 units in non-embolized patients. Transfusion frequencies of $30-55 \%$ have been reported $(12,13,22)$; in the present study, the transfusion frequency was $20.6 \%$, which was close to that reported by Blackmore et al (13). Burgess et al (3) determined a progressively larger mean transfusion volume with the progression from grade I to III in the APC and LC fracture types. However, more frequent pelvic fracture-associated injuries were also reported as the severity of pelvic fracture increased, likely contributing to the increased transfusion volume.

Previous studies have defined the timing of blood transfusion from 24 (12), 48 (14) to $72 \mathrm{~h}$ (13) after admission. In the present study, patients with pelvic fracture were transported to our Level I Trauma Centre within $2 \mathrm{~h}$ from the trauma with the aid of a medical rescue system. Blood transfusion was performed in the initial $6 \mathrm{~h}$ after pelvic fracture, based on the results of physical examination and clinical symptoms of shock.

The blood transfusion frequency and volume in the present study was similar to that in the study by Burgess et al (3). C-type pelvic fractures require a considerably larger blood transfusion volume, with almost $60 \%$ of patients requiring transfusion. However, the same result was reported for the APC III type $(3,12)$. The considerably larger mean transfusion volume in the APC III type in Burgess' study compared with that in the present study supports this conclusion, since the $\mathrm{C} 1$ type in the AO classification system corresponds to the APC III type in that of Young and Burgess.

In the present study, $\sim 50 \%$ pelvic fracture patients (types B and C) received blood transfusions of $>1,500 \mathrm{ml}$. Similarly, unstable pelvic fractures, including APC II, APC III and LC III injuries, received a high blood transfusion volume $(3,5,8,12,22)$.

In addition, patients with pelvic fractures were classified into subtypes according to the AO classification system. The blood transfusion frequency and volume were analysed in association with the subtypes. The B3 subtype of pelvic fracture had the highest transfusion frequency $(53.6 \%)$, which was consistent with the results of Magnussen et al (12). Nearly $70 \%$ of patients of the $\mathrm{C} 3$ subtype received a blood transfusion volume of $>1,500 \mathrm{ml}$. In the present analysis, the AO classification system was proven to be as effective as the system of Young and Burgess (26).

In the present study, massive blood transfusion was defined as $>1,500 \mathrm{ml}$. The results indicated that $\mathrm{C}$-type pelvic fractures are more likely to require massive blood transfusion. The same results were reported in other studies $(12,13,22)$.

The ISSs of unstable pelvic fractures (types B and C) were higher than those for type $\mathrm{A}$, due to the severity of pelvic disruptions and associated injuries. This result was consistent with that of Hamill et al (22).

Previous studies reported an overall mortality of $10-26 \%(5,13,27)$, while that for type $\mathrm{C}$ was $20 \%$ (3). The overall mortality in the present study was $1.8 \%$ and that of type $\mathrm{C}$ was $\leq 10.3 \%$, which was inconsistent with the results of the aforementioned studies $(3,5,13,27)$. High ISS, severe associated injuries and massive blood transfusion volume are recognized as risk factors for mortality in patients with pelvic fracture $(1,4)$. In the present study, multiple traumas were observed in those patients that died, with the associated injuries and high blood loss volume proving to be risk factors for mortality. Of those patients, $>2,000 \mathrm{ml}$ blood transfusion was required for patients with C-type pelvic fractures in the initial $6 \mathrm{~h}$, which required addition intensive care. The blood transfusion volume required in the initial $6 \mathrm{~h}$ for patients who died with types A and B were $>1,000 \mathrm{ml}$ and $1,500 \mathrm{ml}$, respectively. This result from the patients who died suggested an association between the blood transfusion volume and the pelvic fracture type. However, statistical analysis was not performed due to the limited numbers of types, which was another limitation of present study.

Paydar et al (1) developed a system to determine whether patients were in good or poor condition. Patients in poor condition had a lower $\mathrm{pH}$, base excess and hemoglobin level, and required more packed red cell transfusion and a larger volume of infused intravenous fluid.

In the present study, all pelvic fractures were defined as closed injuries. Open pelvic fractures with combined devastating soft-tissue injuries have been reported to have relatively higher transfusion requirements and a higher mortality rate (28). Hasankhani and Omidi-Kashani (28) reported on 15 cases of open pelvic fracture associated with extensive perineal injury. The average blood transfusion volume was 8 packed red blood cell units (range, 4-21 units). A total of 2 patients with APC type III fractures were in deep shock, 1 
Table VI. Hospital stay and ICU days.

\begin{tabular}{lccccc}
\hline AO type & Total patients & Patients in hospital [n, $(\%)]$ & Hospital stay (days) & Patients in ICU [n, (\%)] & ICU stay (days) \\
\hline A & 395 & $69(17.5)$ & $10 \pm 2.0$ & 0 & 0 \\
B & 63 & $42(66.7)$ & $14 \pm 4.1$ & $24(38.1)$ & $3 \pm(89.7)$ \\
C & 39 & $39(100)$ & $24 \pm 3.8^{\mathrm{a}}$ & $18 \pm 6.5$ & $59(11.9)$ \\
Total & 497 & $150(30.2)$ & $18 \pm 4.7^{\mathrm{a}}$ & $9 \pm 7.3$ \\
\hline
\end{tabular}

${ }^{\mathrm{a}} \mathrm{P}<0.01$ vs. fracture $\mathrm{A}$ and $\mathrm{B}$. Values are expressed as the mean \pm standard deviation or $\mathrm{n}(\%)$. AO, Arbeit Fuer Osteosynthese; ICU, intensive care unit.

Table VII. Mortality and morbidity.

\begin{tabular}{lccc}
\hline $\begin{array}{l}\text { AO } \\
\text { type }\end{array}$ & Mortality & Morbidity & $\begin{array}{l}\text { Volume of blood } \\
\text { transfusion }(\mathrm{ml})\end{array}$ \\
\hline A & $1(0.3)$ & $395\left(30.5^{\mathrm{a}}\right)$ & 1,200 \\
B & $4(6.3)$ & $63(4.8)$ & 1,686 \\
C & $4^{\text {b }(10.3)}$ & $39(3.0)$ & 2,100
\end{tabular}

${ }^{\mathrm{a}} \mathrm{P}<0.01, \mathrm{~F}=2, \chi^{2}=28.3328$, vs. fracture $\mathrm{B}$ and $\mathrm{C}$. and ${ }^{\mathrm{b}} \mathrm{P}<0.0001$ vs. fracture $\mathrm{A}$ and $\mathrm{B}$. Values are expressed as the mean \pm standard deviation or $\mathrm{n}(\%)$. AO, Arbeit fuer Osteosynthese.

received 21 units of blood and survived, and 1 received 18 units and died post-operatively due to an associated intra-abdominal injury. The blood transfusion and mortality rates in that study were considerably higher than those in the present one.

The optimal treatment strategy would take into consideration the hemodynamic status, disruptions of the pelvic ring and associated injuries. The aim of pelvic fracture patient management is to definitively restore hemodynamic and mechanical stability of the pelvic ring and repair associated injuries. The management of trauma must therefore be multidisciplinary and ultimately based on the physiology of the patient and the mechanism of the injury $(29,30)$.

In the present study, a strong association was observed between blood transfusion volume and frequency in the initial $6 \mathrm{~h}$ and pelvic fracture type, and the subtypes with the highest transfusion frequency and largest blood transfusion volume were identified. Previous studies, which examined pelvic fracture types and attempted to assess whether the type may predict the outcome, have been limited by the time of transfusion and classification systems for pelvic fractures. In the present study, by demonstrating the marked association between pelvic fracture type and clinical outcome, including blood transfusion, it was indicated that pelvic fracture types may be used as an AO predictor of pelvic blood transfusion and help develop and validate a clinical prediction rule that relies on immediately obvious clinical factors, including fracture type and emergency department presentation, defining clinical predictors that may identify patients that are highly likely to require massive blood transfusion.

The present study had several significant limitations. First, the study was a retrospective, single-center investigation with the associated limitations. Furthermore, pelvic fracture-associated injuries, which may have led to an increase in the requirement for blood transfusion, were not entirely excluded from the study. However, separation of pelvic fractures and associated injuries may not represent the real severity of trauma and the overall amount of hemorrhage. Finally, patients with pelvic fracture may have delayed hemorrhage in the initial $6 \mathrm{~h}$ after pelvic fracture.

In conclusion, patients with $\mathrm{AO}$ fracture type A, B and C resulting from high-energy pelvic impact had a progressively larger mean transfusion volume, transfusion frequency and mortality in the initial $6 \mathrm{~h}$ after pelvic fracture. The B3 subtype was indicated to have the highest frequency of blood transfusion and the C3 subtype required the largest blood transfusion volume. The AO classification system is an effective and validated protocol for investigations on pelvic fracture.

\section{Acknowledgements}

Not applicable.

\section{Funding}

No funding was received.

\section{Availability of data and materials}

All the data and materials are available from the corresponding author on reasonable request, as applicable.

\section{Authors' contributions}

QY, KJ and XT were responsible for case collection; TW was responsible for statistical analysis; LA and DG were responsible for calculating volumes of blood transfusion; YF, NC and FP were responsible for analysis of clinical information.

\section{Ethics approval and consent to participate}

This study was approved by the ethics committee of Qingpu Branch, Zhongshan Hospital affiliated to Fudan University (approval no. 201914; Shanghai, China).

\section{Patient consent for publication}

Not applicable. 


\section{Competing interests}

The authors declare that they have no competing interests.

\section{References}

1. Paydar S, Chaabi M, Akhavan M, Ghahramani Z and Dehghankhalili M: Outcome determinants of patients with traumatic pelvic fractures: A cohort study in a level i trauma center in southern iran. Malays Orthop J 11: 23-30, 2017.

2. Rehwald R, Schönherr E, Petersen J, Jeske HC, Fialkovska A, Luger AK, Grams AE, Loizides A, Jaschke W and Glodny B: Prognostic factors in endovascular treated pelvic haemorrhage after blunt trauma. BMC Surg 17: 89, 2017.

3. Burgess AR, Eastridge BJ, Young JW, Ellison TS, Ellison PS Jr, Poka A, Bathon GH and Brumback RJ: Pelvic ring disruptions: Effective classification system and treatment protocols. J Trauma 30: 848-856, 1990.

4. Starr AJ, Griffin DR and Reinert CM, Frawley WH, Walker J, Whitlock SN, Borer DS, Rao AV and Jones AL: Pelvic ring disruptions: Prediction of associated injuries, transfusion requirement, pelvic arteriography, complications, and mortality. J Orthop Trauma 16: 553-561, 2002.

5. Dalal SA, Burgess AR, Siegel JH, Young JW, Brumback RJ, Poka A, Dunham CM, Gens D and Bathon H: Pelvic fracture in multiple trauma: Classification by mechanism is key to pattern of organ injury, resuscitative requirements, and outcome. J Trauma 29: 981-1002, 1989.

6. Papadopoulos IN, Kanakaris N, Bonovas S, Triantafillidis A, Garnavos C, Voros D and Leukidis C: Auditing 655 fatalities with pelvic fractures by autopsy as a basis to evaluate trauma care. J Am Coll Surg 203: 30-43, 2006.

7. Chen TW, Yang ZG, Dong ZH, Tang SS, Chu ZG and Shao H: Earthquake-related pelvic crush fracture vs. non-earthquake fracture on digital radiography and MDCT: A comparative study. Clinics (Sao Paulo) 66: 629-634, 2011

8. Eastridge BJ, Starr A, Minei JP, O'Keefe GE and Scalea TM: The importance of fracture pattern in guiding therapeutic decision-making in patients with hemorrhagic shock and pelvic ring disruptions. J Trauma 53: 446-451, 2002.

9. Vaidya R, Waldron J, Scott A and Nasr K: Angiography and embolization in the management of bleeding pelvic fractures. J Am Acad Orthop Surg 26: e68-e76, 2018.

10. Hussami M, Grabherr S, Meuli RA and Schmidt S: Severe pelvic injury: Vascular lesions detected by ante- and post-mortem contrast medium-enhanced CT and associations with pelvic fractures. Int J Legal Med 131: 731-738, 2017.

11. Burlew CC, Moore EE, Stahel PF, Geddes AE, Wagenaar AE, Pieracci FM, Fox CJ, Campion EM, Johnson JL and Mauffrey C: Preperitoneal pelvic packing reduces mortality in patients with life-threatening hemorrhage due to unstable pelvic fractures. J Trauma Acute Care Surg 82: 233-242, 2017.

12. Magnussen RA, Tressler MA, Obremskey WT and Kregor PJ: Predicting blood loss in isolated pelvic and acetabular high-energy trauma. J Orthop Trauma 21: 603-607, 2007.

13. Blackmore CC, Jurkovich GJ, Linnau KF, Cummings P, Hoffer EK and Rivara FP: Assessment of amount of hemorrhage and outcome from pelvic fracture. Arch Surg 138: 504-509, 2003

14. Blackmore CC, Cummings P, Jurkovich GJ, Linnau KF, Hoffer EK and Rivara FP: Predicting major hemorrhage in pelvic fracture. J Trauma 61: 346-352, 2006.
15. Marsh JL, Slongo TF, Agel J, Broderick JS, Creevey W, DeCoster TA, Prokuski L, Sirkin MS, Ziran B, Henley B and Audigé L: Fracture and dislocation classification compendium -2007: Orthopaedic trauma association classification, database and outcomes committee. J Orthop Trauma 21 (10 Suppl): S1-S133, 2007.

16. Association for the Advancement of Automotive Medicine (AAAM): The abbreviated injury scale (AIS)-1990 revision. AAAM, Chicago, IL, pp11-15, 1990.

17. Baker SP, O'Neill B, Haddon W Jr and Long WB: The injury severity score: A method for describing patients with multiple injuries and evaluating emergency care. J Trauma 14: 187-196, 1974.

18. American College of Surgeons Committee on Trauma: Advanced Trauma Life Support for Doctors. American College of Surgeons, Chicago, IL, 2004.

19. Lal DS and Shaz BH: Massive transfusion: Blood component ratios. Curr Opin Hematol 20: 521-525, 2013.

20. Miller PR, Moore PS, Mansell E, Meredith JW and Chang MC: External fixation or arteriogram in bleeding pelvic fracture: Initial therapy guided by markers of arterial hemorrhage. J Trauma 54: 437-443, 2003.

21. Tang $\mathrm{CH}$, Shivji F and Forward D: Major haemorrhage in pubic rami fractures. BMJ Case Rep: bcr2014208088, 2015.

22. Hamill J, Holden A, Paice R and Civil I: Pelvic fracture pattern predicts pelvic arterial hemorrhage. Aust N Z J Surg 70: 338-343, 2000.

23. Barratt RC, Bernard J, Mundy AR and Greenwell TJ: Pelvic fracture urethral injury in males-mechanisms of injury, management options and outcomes. Transl Androl Urol 7 (Suppl 1): S29-S62, 2018.

24. Jang JY, Shim H, Jung PY, Kim S and Bae KS: Preperitoneal pelvic packing in patients with hemodynamic instability due to severe pelvic fracture: Early experience in a Korean trauma center. Scand J Trauma Resusc Emerg Med 24: 3, 2016.

25. Sarin EL, Moore JB, Moore EE, Shannon MR, Ray CE, Morgan SJ and Smith WR: Pelvic fracture pattern does not always predict the need for urgernt embolization. J Trauma 58: 973-977, 2005.

26. Osterhoff G, Scheyerer MJ, Fritz Y, Bouaicha S, Wanner GA, Simmen HP and Werner CM: Comparing the predictive value of the pelvic ring injury classification systems by Tile and by Young and Burgess. Injury 45: 742-747, 2014.

27. Gustavo Parreira J, Coimbra R, Rasslan S, Oliveira A, Fregoneze $\mathrm{M}$ and Mercadante $\mathrm{M}$ : The role of associated injuries on outcome of blunt trauma patients sustaining pelvic fractures. Injury 31: 677-682, 2000.

28. Hasankhani EG and Omidi-Kashani F: Treatment outcomes of open pelvic fractures associated with extensive perineal injuries. Clin Orthop Surg 5: 263-268, 2013.

29. Coccolini F, Stahel PF, Montori G, Biffl W, Horer TM, Catena F, Kluger Y, Moore EE, Peitzman AB, Ivatury R, et al: Pelvic trauma: WSES classification and guidelines. World J Emerg Surg 12: 5, 2017

30. Jovanovic B, Milan Z, Djuric O, Markovic-Denic L, Karamarkovic A, Gregoric P, Doklestic K, Avramovic J, Velickovic J and Bumbasirevic V: Twenty-eight-day mortality of blunt traumatic brain injury and co-injuries requiring mechanical ventilation. Med Princ Pract 25: 435-441, 2016.

This work is licensed under a Creative Commons Attribution-NonCommercial-NoDerivatives 4.0 International (CC BY-NC-ND 4.0) License. 